\title{
Research Article \\ EVALUATION OF MONOCROTOPHOS DEGRADATION BY Lysinibacillus sphaericus JX012235 ISOLATED FROM SWINE WASTE
}

\author{
MEIGNANALAKSHMI $S .{ }^{1 *}$, DEEPIKA J. ${ }^{2}$, CHARULATHA M. ${ }^{3}$ AND VIJAYARANI K. ${ }^{4}$ \\ 1,3,4Department of Animal Biotechnology, Madras Veterinary College, Tamil Nadu Veterinary and Animal Sciences University, Chennai, 600007, Tamil Nadu \\ 2Department of Biotechnology, SRM University, Kattankulathur, Chennai, Tamil Nadu 603203 \\ *Corresponding Author: Email-smeignanalakshmi@gmail.com
}

Received: January 25, 2018; Revised: February 16, 2018; Accepted: February 17, 2018; Published: February 28, 2018

\begin{abstract}
In India, the mainly used pesticide in agricultural crops is Monocrotophos, an organophosphorus pesticide. It is denoted as extremely toxic and their exposure to environment is considered to be lethal. In this study, degradation of Monocrotophos by Lysinibacillus sphaericus JX012235 a bacterium isolated from swine waste was studied. Growth studies of the bacteria in mineral salt broth supplemented with the pesticide at the concentration of 100-1000 ppm initially confirmed the degradation of the pesticide. The bacterium was found to survive when pesticide was given as a sole source of nutrition. The pesticide degradation was confirmed by LC-MS. The phosphatase activity of bacterium was found to be $69 \mathrm{U} / \mathrm{ml}$.
\end{abstract}

Keywords- Monocrotophos, Lysinibacillus sphaericus, Biodegradation, Swine waste, Phosphatase activity.

Citation: Meignanalakshmi S., et al., (2018) Evaluation of Monocrotophos degradation by Lysinibacillus sphaericus JX012235 Isolated from Swine Waste. International Journal of Microbiology Research, ISSN: 0975-5276 \& E-ISSN: 0975-9174, Volume 10, Issue 2, pp.-1011-1014. DOl: http://dx.doi.org/10.9735/0975-5276.10.2.1011-1014

Copyright: Copyright@2018 Meignanalakshmi S., et al., This is an open-access article distributed under the terms of the Creative Commons Attribution License, which permits unrestricted use, distribution and reproduction in any medium, provided the original author and source are credited.

Academic Editor / Reviewer: B.L. Raghunandan, Trupti B. Naik

\section{Introduction}

The growing population of the world has given more pressure to the field of agriculture in terms of food, nutrition etc. Hence there has been a huge utilization of technology, new varieties and short term crops, usage of fertilizers, pesticides and insecticides to increase the crop yield. The agricultural land should be supplied with a minimal amount of chemicals so that it does not affect the land's fertility and the water washed off to rivers. The commonly used pesticides are Monocrotophos, Dichlorovos (Orthophosphates), Parathion, Diazinon (Organophosphates), Vamidothion (Thiolphosphates), Phorate, Malathion (Dithiophosphates) and Trichlorophon (Phosphonates). These pesticides have their own permissible levels in land. However, if the concentration exceeds the normal level the fertility of the soil is lost and the pesticide retains there causing environmental pollution. The pesticide infestation in soil can cause severe problems like 1) alterations of ecological balance, 2) loss of common soil microflora 3) Less soil fertility and crop productivity 4) Interference with ammonification in soil 5) alterations in rhizosphere microflora 6) absorption of pesticides by plants. Monocrotophos, a relatively cheap pesticide is principally used in agriculture. Wistar rats in a recent study were administered with $1 / 50$ th of $L D_{50}$ dosage of monocrotophos $(0.36 \mathrm{mg} / \mathrm{kg}$ body weight) for three weeks orally. Dyslipidemia and mild hyperglycemic conditions was observed in blood when monocrotophos was administered in animals. Cardiac oxidative stress was conferred by accumulation of protein carbonyls, lipid peroxidation and glutathione production [1]. Monocrotophos on contact is highly toxic to organisms, including humans [2]. The Lysinibacillus sp which was isolated from contaminated agricultural soil was found to degrade fomesafen, an herbicide and it was identified using the comparative analysis of 16srRNA gene [3]. However, there are only few reports where Lysinibacillus sphaericus has been used in the pesticide degradation. Swine waste from pig farm is often used as manure in agricultural land. When manure is used on the agricultural land, the impact on the environment has to be considered. If the manure has got the ability to degrade pesticides and heavy metals it will be more useful for farmers. Hence the present study is aimed to isolate and to find out if there is any pesticide degrading bacteria present in the swine waste

In this study Lysinibacillus sphaericus isolated from swine waste was tested for the efficacy of pesticide degradation. Lysinibacillus sphaericus, a Gram-positive, mesophilic, rod-shaped bacterium is known for its bioremediation capability. It was initially isolated from a mosquito breeding site in China in 1987 [4].This bacterium was found to be more effective in pesticide degradation. It can surely be used for the direct application in the agricultural field because of its capacity to grow in low nutrition conditions.

\section{Materials and Methods Isolation and Identification of Bacteria from swine waste \\ Fresh swine waste was collected from TANUVAS Research Station, Kattupakkam and the filtrate was prepared using $10 \mathrm{~mL}$ of Sterile Distilled water. The sample was then serially diluted and the bacterial colonies have been isolated from different dilutions ranging from $10^{-6}$ to $10^{-9}$. The bacterium was then streaked repeatedly in nutrient agar to obtain pure cultures. The isolated strain was then identified by biochemical tests using himedia Biochemical test kit (KB001) and 16s rRNA sequencing using the primers: Forward - 8F (5' - GAGTTTGATCATGGC TCAG-3') Reverse - 1495r (5'-CTACGGCTACCTTGTTACG-3') [5].}

\section{Evaluation of Pesticide degradation by Lysinibacillus sphaericus}

The Bacteria Isolated from Swine Waste Was tested for degrading Monocrotophos $(36 \% \mathrm{SL})$. The bacterium was initially inoculated both in Mineral salt agar devoid of carbon source $\left(\mathrm{MgSO}_{4}-0.05 \mathrm{~g}, \mathrm{Fe}\left(\mathrm{SO}_{4}\right)_{3}-0.01 \mathrm{~g}, \mathrm{NaNO}_{3}-2.0 \mathrm{~g}, \mathrm{KH}_{2} \mathrm{PO}_{4}-\right.$ $0.14 \mathrm{~g}, \mathrm{~K}_{2} \mathrm{HPO}_{4}-1.2 \mathrm{~g}, \mathrm{KCl}-0.5 \mathrm{~g}$, Yeast extract $-0.02 \mathrm{~g}$, Agar $-15 \mathrm{~g}, \mathrm{pH}-7.2$ ) and Mineral salt medium (MSM) supplemented with pesticide in the range of 100 - 
1000ppm respectively under aseptic conditions. Uninoculated media with the pesticide served as a control. The MSM containing test tubes were incubated under shake culture condition (100rpm) at $37^{\circ} \mathrm{C}$ for 6 days. Each day the absorbance was checked in UV spectrophotometer at $600 \mathrm{~nm}$. The growth curve was plotted accordingly to know the actual growth of the bacterium.

\section{Medium optimisation with Monochrotophos}

The bacterium was then inoculated in modified Mineral salt medium supplemented with 1000ppm of Monocrotophos i.e MSM without $\mathrm{MgSO}_{4}, \mathrm{MSM}$ without $\mathrm{FeSO}_{4}$ MSM without $\mathrm{KCl}$, MSM without $\mathrm{K}_{2} \mathrm{HPO}_{4}$, MSM without $\mathrm{KH}_{2} \mathrm{PO}_{4}$ and MSM without $\mathrm{NaNO}_{3}$. In all these media, the yeast extract was neglected to remove the nitrogen source completely. The bacterium was inoculated in the above prepared sterilized media individually and their growth was checked in UV-Spectrophotometer at an absorbance of $600 \mathrm{~nm}$. In this experiment, the bacteria was inoculated in $2 \%$ pesticide agar containing maximum amount of Monocrotophos -1000ppm and 2000ppm and tested whether it could be able to grow only in the presence of pesticide without any additional nutrients. The growth was monitored continuously for 7 days [6\&7].

\section{LC-MS analysis of Monochrotophos degradation}

After the optimization of Monocrotophos degradation by testing them in various media containing nutrients as well as MCP of about 1000ppm, the sample was collected at the end of $7^{\text {th }}$ day and centrifuged at 8000 rpm for 25 minutes. The cell-free supernatant was estimated for residual content of Monocrotophos by LCMS (Model -LCMS 2020 Shimadzu) using UV detector. The column used was C18 reverse phase Column with size $250 \times 4 \mathrm{~mm} .5$ micron size. The operating conditions were as follows: column temperature $-32^{\circ} \mathrm{C}$; mobile phase, $20 \%$ acetonitrile in water; flow rate $0.2 \mathrm{ml} \mathrm{min}^{-1}$; volume of sample injected, $3 \mu$ l. Standard aqueous solution of Monocrotophos of concentration 1000ppm was tested in LC-MS which served as a control [8].

\section{Determination of Phosphatase activity}

Alkaline phosphatase activity was measured by the release of $p$-nitrophenol from p-nitrophenyl phosphate (pNPP) at 400nm [9]. A typical reaction mixture contained $100 \mu \mathrm{l}$ of enzyme diluted in $2 \mathrm{ml}$ of $200 \mathrm{mM}$ Tris buffer (pH 8.5), $100 \mu \mathrm{l}$ of $5 \mathrm{mM}$ $\mathrm{CaCl}_{2}, 100 \mu \mathrm{l}$ of $500 \mu \mathrm{mol}$ pNPP and the final volume was made up to $3 \mathrm{ml}$ using distilled water. Blank was prepared by mixing $2 \mathrm{ml}$ of $200 \mathrm{mM}$ Tris buffer (pH 8.5) and $1 \mathrm{ml}$ distilled water. The reaction was performed at $37^{\circ} \mathrm{C}$ for $30 \mathrm{~min}$ and stopped by addition of $500 \mu \mathrm{l}$ of $4 \mathrm{M}$ sodium hydroxide. One unit of phosphatase is the amount, which hydrolyses $1 \mu \mathrm{mol}$ of substrate per min. The standard curve obtained by absorbance of $p$-nitrophenol $(0-500 \mu \mathrm{mol})$ at $400 \mathrm{~nm}$ was used for quantification of enzyme activity [10].

\section{Results}

\section{Isolation and Identification of pesticide degrading bacteria:}

Totally five isolates designated as D1, D2, D3, D4 and D5 obtained from the swine waste have been checked for the pesticide degradation. Among this D2 had the maximum capacity to grow in Minimal salt agar supplemented with the pesticide. The culture D2 was identified as Lysinibacillus sphaericus by 16s rRNA sequencing. The obtained sequence was deposited in the Genbank and the strain and accession number obtained are DMS-3 and JX012235. The phylogenetic tree for the bacteria and the photomicrograph is given in [Fig-1a) and 1b)] respectively.

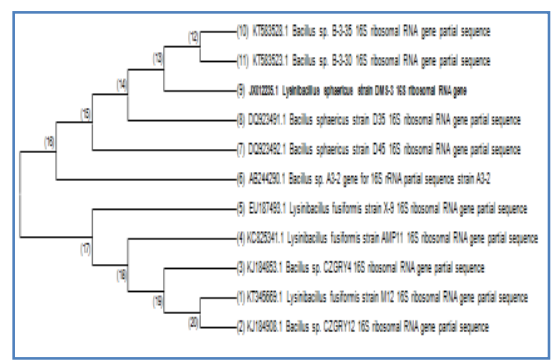

Fig-1 a) Phylogenetic tree of Lysinibacillus sphaericus JX012235

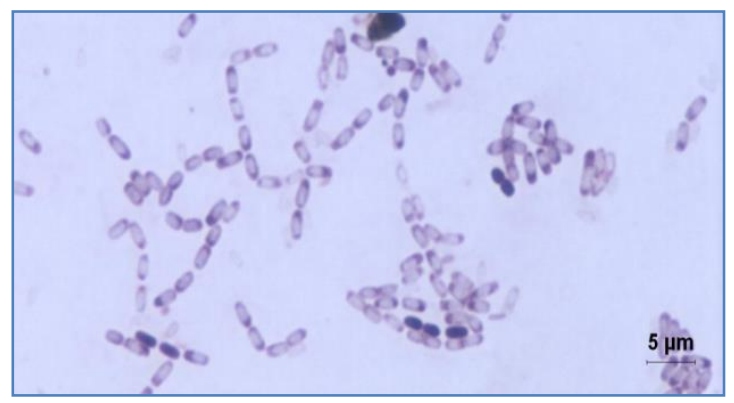

Fig-1 b) Photomicrograph of Lysinibacillus sphaericus (1000X)

\section{Evaluation of Pesticide degradation by Lysinibacillus sphaericus}

The growth curve was plotted [Fig-2]. It was found that the growth was very prominent in media containing MCP of concentration 100ppm and minimum growth was observed at the maximum concentration of 1000ppm.

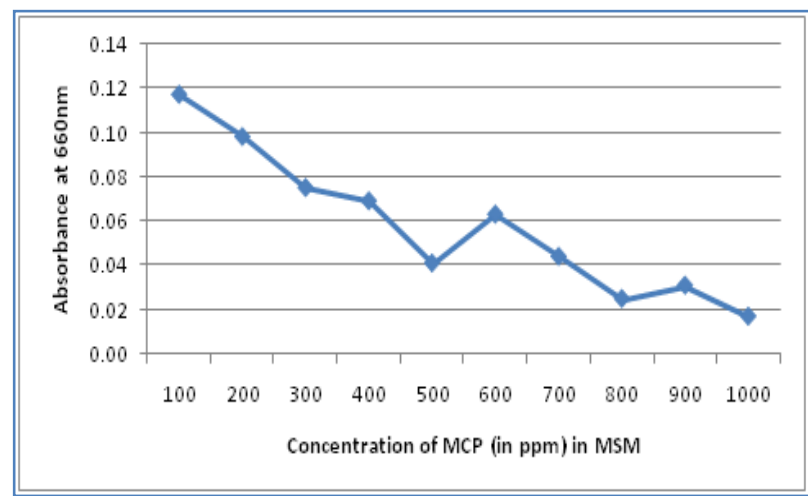

Fig-2 Growth of Lysinibacillus sphaericus in MSM supplemented with MCP after 6 days of incubation

\section{Medium optimisation with Monochrotophos}

Lysinibacillus sphaericus was able to grow in the absence of $\mathrm{K}_{2} \mathrm{HPO}_{4}, \mathrm{KH}_{2} \mathrm{PO}_{4}$ and $\mathrm{FeSO}_{4}$. However, the growth was negligible when $\mathrm{NaNO}_{3}, \mathrm{KCl}$ and $\mathrm{MgSO}_{4}$ were not added in the MSM.

The bacteria were able to grow in MCP agar containing 1000ppm MCP after 2 days. And no growth was observed when MCP of about 2000ppm was added to the agar. This has partially confirmed that the bacterium has started to break the pesticide and utilize it as a sole carbon source. Hence, this study will have a significant effect in the pesticide degradation as it has more possibility of growing independent of the basic nutrients.

\section{LC-MS analysis of Monochrotophos degradation}

The peaks obtained in LC-MS for both the control and test sample at different retention showed the degradation of the pesticide. The positive and negative values of the LC-MS graphs are given in the [Fig-3]. In control the peaks for MCP were found at 2.009, 2.379, 2.587, 8.299, 8.563, 9.424, 9.734, 11.026, 12.741, 14.260, 15.555 and 16.487. In Lysinibacillus sphaericus with 1000ppm MCP the following peaks which were found in the control were absent 2.009, 8.299, 15.555 and 16.487

\section{Determination of Phosphatase activity}

The Phosphatase activity was checked by the chemical assay which indicated that Lysinibacillus sphaericus had the ability to breakdown the $\mathrm{p}$-nitrophenol phosphate (PNPP) to p-nitro phenol and phosphate. The enzyme activity was $69 \mathrm{U} / \mathrm{ml}$. This result confirmed that the bacteria produce phosphatase and by this mechanism also it would have cleaved the Monocrotophos, an organ phosphorus pesticide.

\section{Discussion}

This is the first report of Lysinibacillus sphaericus being used for the pesticide degradation especially Monocrotophos, an organ phosphorus compound. Lysinibacillus sp was also reported for fomesafen, an herbicide degradation which 
was isolated from contaminated agricultural soil. The strain was reported to utilise fomesafen as the sole carbon source for growth and the total degradation rate was $81.32 \%$ after 7 days of incubation [3].

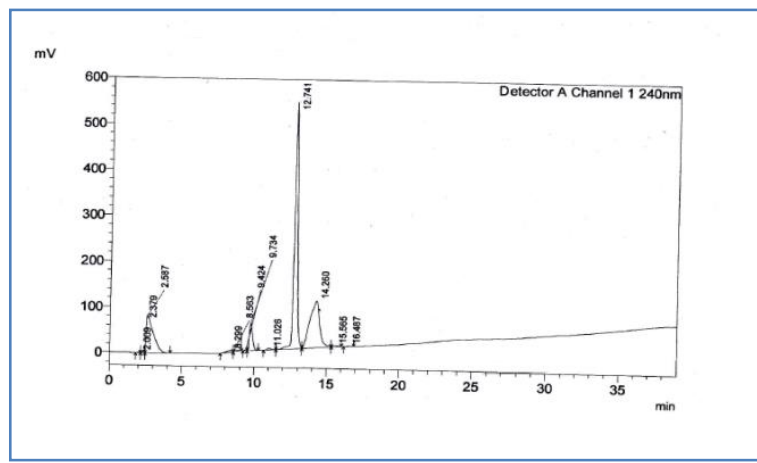

Fig-3 a) HPLC peaks of the control Monocrotophos (1000ppm) at various retention time

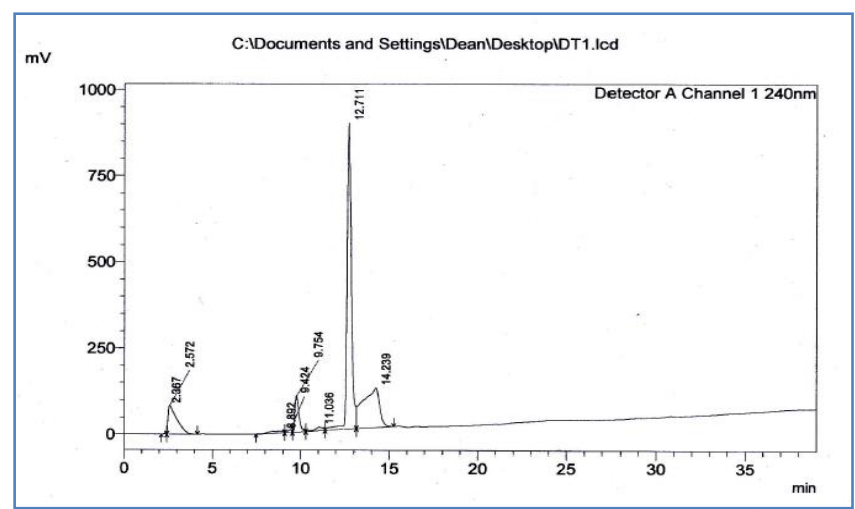

Fig-3 b) HPLC peaks of Lysinibacillus sphaericus with 1000ppm MCP at various retention time

Monocrotophos degradation by Paracoccus sp M-1 isolated from sludge of a wastewater treatment system was reported by Jia et al. They reported that Paracoccus sp M-1 could use MCP as a sole carbon source and also reported $79.92 \%$ degradation of MCP after 6hrs of incubation. The degradation of the pesticide supported cell growth indicating that $M-1$ could utilise it [11]. In the present study Lysinibacillus sphaericus could also use MCP as sole source of carbon without addition of any nutrients. MCP degrading Aspergillus sp. and Pseudomonas aeruginosa was isolated from the soil contaminated with monochrotophos by Athul Sanjeev and Roopa [12]. Srinivasulu et al., isolated MCP degrading $R$. phenolicus strain MCP1 and $R$. ruber strain MCP-2 from soil and reported 30 to $45 \%$ mineralization of monocrotophos when compared to the uninoculated control at the end of 4th day incubation [13]. MCP degrading microbes have been isolated by Sidhu et al., from the contaminated soil and reported $68 \%$ of MCP degradation after 17 days of incubation [14].

Rachna Jain and Veena Garg studied the extracellular fungal hydrolase secreted by Aspergillus niger which degraded MCP and reported residual MCP concentration of $64.94 \pm 0.42$ and $16.95 \pm 0.55 \mu \mathrm{g} / \mathrm{ml}$ after 15 days of incubation for microbial and enzymatic method respectively [15]. In our study Lysinibacillus sphaericus was able to produce phosphatase $69 \mathrm{U} / \mathrm{ml}$ which could be the enzyme responsible for MCP degradation.

Phosphotriesterase which degrade organ phosphorus pesticide have been reported by Kumar et al., by a species of Flavobacterium M-1 and the degradation of pesticide was by the presence of phosphatase and amide enzymes in M-1 [16] and it appeared that the pathway for the biodegradation of Monocrotophos is similar to that previously studied in Arthrobacter atrocyananeus MCM B-425 and Bacillus megatherium MCM B-423 [11]. They reported complete degradation of MCP by LC-MS analysis after 5 days of incubation.
Lysinibacillus sphaericus has the capacity to grow in adverse conditions and they form spores during the unfavourable conditions. In the present study Lysinibacillus sphaericus isolated from swine waste could possibly be used in pesticide contaminated soil for Monocrotophos degradation.

\section{Conclusion}

Lysinibacillus sphaericus isolated from swine waste have been found to degrade monochrotophos and can be used in future for Biodegradation of monochrotophos in pesticide polluted soil.

Application of Research: This study could be useful for biodegradation of Monochrotophos polluted soil.

\section{Research Category: Bioremediation}

Abbreviations: ppm- parts per million, LD- lethal dose, LC-MS - Liquid chromatography Mass spectrometry, MSM- mineral salt medium, MCP Monochrotophos

Acknowledgment: Author are thankful to Madras Veterinary College, Tamil Nadu Veterinary and Animal Sciences University, Chennai, 600007, Tamil Nadu

* Principle Investigator: Meignanalakshmi S.

University: Tamil Nadu Veterinary and Animal Sciences University, Chennai, Tamil Nadu 600051

Research project name or number: Nil

Author Contributions: All author equally contributed

Author statement: All authors read, reviewed, agree and approved the final manuscript.

\section{Conflict of Interest: None declared}

Ethical approval: This article does not contain any studies with human participants or animals performed by any of the authors.

\section{References}

[1] Velmurugan G., Venkatesh Babu D.D. and Ramasamy S. (2013) Toxicology, 307, 103-8.

[2] Isoda H., Talorete T.P., Han J., Oka S., Abe Y. and Inamori Y. (2005) Environmental sciences, 12(1), 9-19.

[3] Bo Liang, Peng Lu, Huihui Li, Rong Li, Shunpeng Li and Xing Huang. (2009) Chemosphere, 77(11), 1614-1619.

[4] Pei G., Oliveira C.M.F., Yuan Z., Nielsen-LeRoux C., Silva-Filha M.H., Yan J. and Regis L. (2002) Appl Environ Microbiol, 68(6), 3003-3009.

[5] Bitan Basu, Ramanathan Ramasamy, Sivasubramanian Viswanathan, lyyappan Divya Priya, Jayarajan Jeyan, Amala Reddy and Vinoth Kumar V. (2014) International Journal of ChemTech Research, 6(10), 4556-4563.

[6] Bhadbhade B.J., Sarnaik S.S. and Kanekar P.P. (2002) J. Appl Microbiol, 93 (2), 224-34.

[7] Olawale A.K. and Akin obi O.A. (2011) Report and Opinion, 3(1), 124-128.

[8] Ismail M, Murtaza Sayed, Hasan M Khan and William J Cooper. (2014) Journal of Analytical \& Bioanalytical Techniques, 5(1), 1-10.

[9] Ram Kumar Dhaked, Syed Imteyaz Alam, Aparna Dixit, Lokendra Singh. (2005) Enzyme and Microbial Technology, 36, 855-861.

[10] Anuradha Thallapaka (2016) International Journal of Recent Research and Applied Studies, 3(10 (12)), 51-61.

[11] Jia K., Cui Z., He J., Guo P. and Li S. (2006) FEMS Microbiol Lett, 263 (2006), 155-162. 
[12] Athul Sanjeev and Roopa P. (2016) Imperial Journal of Interdisciplinary Research, 2(11), 56-59.

[13] Srinivasulu M., Nilanjan P.C., Chakravarthi B.V.S.K., Jayabaskaran C., Jaffer M.G., Naga R.M., Manjunatha B., Darwin R.O., Juan O.T. and Rangaswamy V. (2017) African journal of Biotechnology, 16(9), 401-417.

[14] Sidhu P.K., Dhanjal N.I.K., Cameotra S.S. and Sud D. (2015) Desalination and Water Treatment, 54(8).

[15] Rachna Jain and Veena Garg (2015) J Environ Occup Sci, 4(1), 44-52.

[16] Kumar S., Mukerii K.G. and Lal R. (1996) Critical Reviews in Microbiology, $22(1), 1-26$. 